\title{
Interfacility neurosurgical transfers: an analysis of nontraumatic inpatient and emergency department transfers with implications for improvements in care
}

\author{
Michael M. Safaee, MD, Ramin A. Morshed, MD, Jordan Spatz, PhD, Sujatha Sankaran, MD, \\ Mitchel S. Berger, MD, and Manish K. Aghi, MD, PhD \\ Department of Neurological Surgery, University of California, San Francisco, California
}

OBJECTIVE Interfacility neurosurgical transfers to tertiary care centers are driven by a number of variables, including lack of on-site coverage, limited available technology, insurance factors, and patient preference. The authors sought to assess the timing and necessity of surgery and compared transfers to their institution from emergency departments (ED) and inpatient units at other hospitals.

METHODS Adult neurosurgical patients who were transferred to a single tertiary care center were analyzed over 12 months. Patients with traumatic injuries or those referred from skilled nursing facilities or rehabilitation centers were excluded.

RESULTS A total of 504 transferred patients were included, with mean age 55 years (range 19-92 years); $53 \%$ of patients were women. Points of origin were ED in $54 \%$ cases and inpatient hospital unit in $46 \%$, with a mean distance traveled for most patients of 119 miles. Broad diagnosis categories included brain tumors $(n=142,28 \%)$, vascular lesions, including spontaneous and hypertensive intracerebral hemorrhage $(n=143,28 \%)$, spinal lesions $(n=126,25 \%)$, hydrocephalus $(n=45,9 \%)$, wound complications $(n=29,6 \%)$, and others $(n=19,4 \%)$. Patients transferred from inpatient units had higher rates of surgical intervention $(75 \%$ vs $57 \%, p<0.001)$, whereas patients transferred from the ED had higher rates of urgent surgery ( $20 \%$ vs $8 \%, p<0.001)$ and shorter mean time to surgery ( 3 vs 5 days, $p<0.001)$. Misdiagnosis rates were higher among ED referrals ( $11 \%$ vs $4 \%, p=0.008)$. Across the same timeframe, patients undergoing elective admission $(n=1986)$ or admission from the authors' own ED $(n=248)$ had significantly shorter lengths of stay ( $p$ $<0.001)$ and ICU days $(p<0.001)$ than transferred patients, as well as a significantly lower total cost $(\$ 44,412, \$ 46,163$, and $\$ 72,175$, respectively; $p<0.001$ ).

CONCLUSIONS The authors present their 12-month experience from a single tertiary care center without Level I trauma designation. In this cohort, $65 \%$ of patients required surgery, but the rates were higher among inpatient referrals, and misdiagnosis rates were higher among ED transfers. These data suggest that admitting nonemergency patients to local hospitals may improve diagnostic accuracy of patients requiring urgent care, more precisely identify patients in need of transfer, and reduce costs. Referring facilities may lack necessary resources or expertise, and the Emergency Medical Treatment and Active Labor Act (EMTALA) obligates tertiary care centers to accept these patients under those circumstances. Telemedicine and integration of electronic medical records may help guide referring hospitals to pursue additional workup, which may eliminate the need for unnecessary transfer and provide additional cost savings.

https://thejns.org/doi/abs/10.3171/2018.3.JNS173224

KEYWORDS interfacility; neurosurgery; transfer; tertiary care

$\mathrm{T}$ HE need for acute neurosurgical care is a common indication for interfacility transfer. ${ }^{6,19}$ Most small, community-based hospitals lack full-time neurosurgical coverage. As subspecialists consolidate toward tertiary care or specialized regional centers, the need for neurosurgical transfers will continue to grow. Smaller, rural centers may also lack the capacity for complex diagnostic studies, thus requiring transfer to a higher level of care to rule out dangerous or life-threatening conditions. Neurosurgical evaluation is critical in this process, and in-

ABBREVIATIONS ED = emergency department.

SUBMITTED December 26, 2017. ACCEPTED March 1, 2018.

INCLUDE WHEN CITING Published online August 3, 2018; DOI: 10.3171/2018.3.JNS173224. 
efficient triage and transfer of patients can adversely affect patient outcome and detract resources from true neurosurgical emergencies.

Increasing the presence of local and community neurosurgeons is vital for the medical and surgical management of both traumatic and nontraumatic neurological diseases; however, the need to transfer these patients to tertiary referral centers is unclear and has not been well studied. There are limited data on identifying which patients require care at specialized centers and which can be treated locally. Furthermore, the timing of when these transfers should occur is often subjective. In this study, we performed a retrospective analysis of the transfer patterns to a single tertiary academic center without a Level I trauma designation to understand what portion of neurosurgical transfers were operative and the level of urgency for operative cases, and to define whether the point of origin impacted these variables. Our goal is to use these data to improve our understanding of neurosurgical transfer patterns and promote safe and efficient triage of care.

\section{Methods \\ Data Acquisition}

All research activities were approved by the Committee on Human Research, our institutional review board. Patient transfers to our institution were collected over a 12-month period ranging from July 1, 2015, to July 1, 2016. Information including patient age, sex, point of origin, urgency of transfer, referring hospital and location, insurance type, and cost billed to insurance was acquired from our transfer center and billing department. Study personnel then verified admitting diagnosis, admission to the ICU, length of stay, time to surgery, and discharge disposition through individual reviews of the medical records. In an effort to compare our own elective surgical cases and emergency department (ED) admissions with cases transferred to our institution, information on a separate cohort was acquired based on discharges from July 1, 2015, to July 1, 2016. Need for surgery, length of stay, insurance type, and total cost were compared among these patients.

\section{Statistical Analysis}

Univariate analysis of continuous variables was performed using the Student t-test, and categorical variables were compared using the chi-square test or Fisher's exact test when fewer than 5 variables were analyzed. Statistical significance was defined as $\mathrm{p}<0.05$. All analyses were performed using IBM SPSS (version 22, IBM Corp.).

\section{Results \\ Demographics}

Over a 12-month period spanning a single academic year, our department accepted 535 transfer requests through our transfer center. After exclusion of 29 patients with traumatic injuries and 2 patients referred from skilled nursing facilities or rehabilitation centers, a total of 504 patients were included in our analysis. Patient demographics are summarized in Table 1. The mean age was 55 years (range 19-92 years) with 239 men and 265 women (47\%
TABLE 1. Patient demographics

\begin{tabular}{|c|c|}
\hline Variable & Value \\
\hline No. of patients & 504 \\
\hline Mean age (range), yrs & $55(19-92)$ \\
\hline Female sex & $265(53 \%)$ \\
\hline \multicolumn{2}{|l|}{ Point of origin } \\
\hline ED & $273(54 \%)$ \\
\hline Inpatient hospital & $231(46 \%)$ \\
\hline Emergency transfer & $55(11 \%)$ \\
\hline Mean distance to UCSF (range), miles & $119(1-869)$ \\
\hline \multicolumn{2}{|l|}{ Insurance type } \\
\hline Medicare & $193(38 \%)$ \\
\hline Medi-Cal & $164(33)$ \\
\hline Commercial & $140(28 \%)$ \\
\hline Other & $7(1 \%)$ \\
\hline \multicolumn{2}{|l|}{ Diagnosis } \\
\hline Vascular lesions & 143 \\
\hline $\mathrm{SAH}$ & 64 \\
\hline $\mathrm{ICH}$ & 31 \\
\hline Aneurysm & 17 \\
\hline Cavernous malformation & 12 \\
\hline AVM & 12 \\
\hline Carotid stenosis & 3 \\
\hline DAVF & 2 \\
\hline Moyamoya/revascularization & 2 \\
\hline Brain tumor & 142 \\
\hline Primary tumor & 124 \\
\hline Metastases & 18 \\
\hline Spinal lesions & 126 \\
\hline Infection & 38 \\
\hline Fracture & 21 \\
\hline Degenerative disease & 18 \\
\hline Primary tumor & 14 \\
\hline Metastatic tumor & 13 \\
\hline Pseudarthrosis & 12 \\
\hline Cauda equina syndrome & 6 \\
\hline Other & 4 \\
\hline Hydrocephalus & 45 \\
\hline New diagnosis & 18 \\
\hline Shunt failure & 27 \\
\hline Wound complications & 29 \\
\hline Infection or dehiscence & 21 \\
\hline CSF leak or pseudomeningocele & 8 \\
\hline Other & 19 \\
\hline
\end{tabular}

$\mathrm{AVM}=$ arteriovenous malformation; $\mathrm{DAVF}=$ dural arteriovenous fistula; $\mathrm{ICH}=$ intracerebral hemorrhage; $\mathrm{SAH}=$ subarachnoid hemorrhage; UCSF = University of California, San Francisco.

Values are presented as the number of patients unless stated otherwise.

and $53 \%$, respectively). The point of origin was an outside ED in 273 cases (54\%) and inpatient hospital unit in 231 cases (46\%). Timing of transfer was deemed urgent in 55 cases $(11 \%)$ and nonurgent in 449 cases (89\%). The mean 


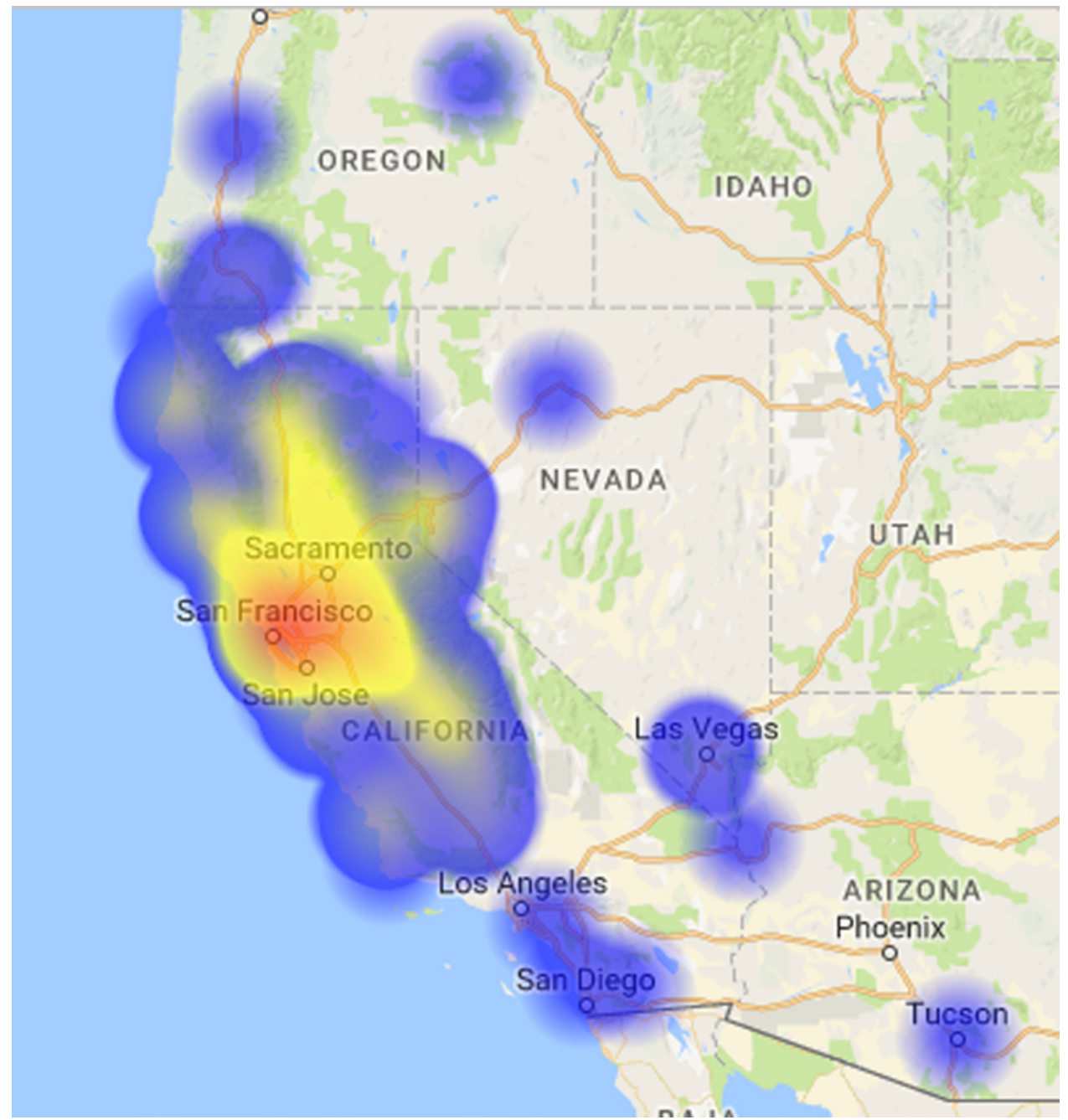

FIG. 1. Geographic distribution of neurosurgical transfers. Heat map demonstrating frequency of transfers based on point of origin. Map data: @2018 Google. Figure is available in color online only.

distance transferred for 482 patients was 119 miles with a range of 1-869 miles (21 cases were excluded, including 2 patients from Hawaii, 4 patients from the Eastern US, and 15 patients without available data). A heat map demonstrating frequency of transfers based on location is provided in Fig. 1. Insurance was classified as Medicare in 193 cases (38\%), Medi-Cal in 164 cases (33\%), commercial in 140 cases (28\%), and other or self-pay in 7 cases (1\%).

\section{Diagnoses}

Diagnoses for each patient were confirmed based on a review of the medical records. Diagnoses were broadly characterized as brain tumor (primary or metastatic), vascular lesions (including spontaneous and hypertensive intracerebral hemorrhage), spinal lesions, hydrocephalus, wound complications, or other. A total of 142 brain tumors were included: 124 primary central nervous system tumors and 18 metastases. Vascular lesions were seen in 143 patients, including 64 with aneurysmal subarachnoid hemorrhage, 31 with intracerebral hemorrhage, 17 with unruptured aneurysms, 12 with cavernous malformations, 12 with arteriovenous malformations, 3 with carotid stenosis, 2 with dural arteriovenous fistulas, and 2 with moyamoya requiring revascularization. There were 126 spinal lesions, including 38 cases of osteomyelitis or epidural abscess, 21 fractures, 18 cases of degenerative disease, 14 primary tumors, 13 metastatic tumors, 12 cases of pseudarthrosis, 6 cases of cauda equina syndrome, and 4 other etiologies. We included 45 cases of hydrocephalus, accounting for 18 new diagnoses and 27 cases of shunt failure. There were 29 wound complications, consisting of 21 infections or dehiscence and $8 \mathrm{CSF}$ leaks or pseudomeningoceles. Nineteen of these patients had their primary surgery at our institution, while 10 had the original surgery at an outside facility. Transfer diagnoses are summarized in Table 1.

\section{Admission and Surgical Characteristics}

Among 504 patients, 240 (48\%) were admitted to the ICU, with 32 of those (13\%) transferred out of the ICU within the first 24 hours. Among 231 transferred inpatients, $174(75 \%)$ were managed surgically during their admission compared with 156 of 273 (57\%) of ED trans- 
fers ( $\mathrm{p}<0.001)$. Among patients who underwent surgery, broad categories included brain tumor in 91 cases (28\%); vascular lesions in 90 cases (27\%); spine lesions in 90 cases (27\%); hydrocephalus or shunt malfunction in 30 cases (9\%); wound complications in 22 cases (7\%); and other etiologies in 7 cases (2\%), which included a variety of diagnoses, including intracranial abscess, idiopathic intracranial hypertension, and trigeminal neuralgia. Patients who underwent surgery had a longer length of stay (13 vs 6 days, $\mathrm{p}<0.001$ ) and a mean time to surgery of 4 days. These patients were also more likely to require discharge to a skilled nursing facility or rehabilitation facility compared with nonoperative patients $(43 \%$ vs $19 \%$, p < 0.001$)$. Data comparing operative and nonoperative cases are summarized in Table 2.

\section{Emergency Department Versus Inpatient Transfers}

There was no significant difference in age $(p=0.110)$ or sex $(p=0.536)$ between ED and inpatient transfer patients. A significantly higher percentage of ED patients were admitted to the ICU $(56 \%$ vs $38 \%, \mathrm{p}<0.001)$ for frequent neurological examinations, mechanical ventilation, external ventricular drain placement, or vasopressors. However, only $51 \%$ of ED patients and $30 \%$ of inpatient unit transfer patients had documented ICU needs on arrival to our facility ( $p<0.001)$. Rates of misdiagnosis were higher among patients transferred from an ED than among those transferred from inpatient units (11\% vs $4 \%, \mathrm{p}=0.008)$. Common misdiagnoses included shunt failure or hydrocephalus in 12 cases where workup was negative, brain or spine tumor in 9 cases where review by our team found no evidence of surgical lesion, wound infection in 3 cases where workup was negative, and cauda equina syndrome in 2 cases, each radiographically normal.

Vascular lesions were more common in patients transferred from an ED (35\% vs $21 \%, \mathrm{p}=0.001)$, while spine lesions were more common among those tranferred from inpatient units $(33 \%$ vs $18 \%, \mathrm{p}<0.001)$. Rates of other diagnoses, including brain tumors, wound complications, and hydrocephalus, were similar between ED and inpatient referrals. Regarding insurance type among patients transferred from outside EDs, $39 \%$ of patients had Medicare, 33\% had Medi-Cal, 27\% had commercial insurance, and $1 \%$ other; for inpatient transfers, $37 \%$ had Medicare, $32 \%$ had Medi-Cal, 29\% had commercial insurance, and $2 \%$ other. These differences were not statistically significant. Data on ED and inpatient transfers are summarized in Table 3.

\section{Analysis of Operative Transfers}

Among patients who underwent surgery, there was a significant difference in age $(p=0.037)$ but not sex $(p=$ $0.769)$ or urgency of transfer $(p=0.292)$ when comparing ED and inpatient referrals. A higher percentage of ED patients were admitted to the ICU (60\% vs $39 \%$, p $<0.001$ ), and a higher number of ED patients had documented ICU needs, such as frequent neurological examinations, mechanical ventilation, external ventricular drain placement, or vasopressors compared with inpatient referrals $(56 \%$ vs $31 \%, \mathrm{p}<0.001)$. Rates of misdiagnosis were
TABLE 2. Comparison of operative and nonoperative cases

\begin{tabular}{|c|c|c|c|}
\hline Variable & Nonop $(n=174)$ & $O p(n=330)$ & p Value \\
\hline Mean age (range), yrs & $56(22-92)$ & $55(19-88)$ & 0.533 \\
\hline Female sex & $88(51 \%)$ & $177(54 \%)$ & 0.513 \\
\hline Emergency transfer & $19(11 \%)$ & $36(11 \%)$ & 0.997 \\
\hline \multicolumn{4}{|l|}{ Point of origin } \\
\hline Inpatient hospital & $57(33 \%)$ & $174(53 \%)$ & $<0.001$ \\
\hline ED & $117(67 \%)$ & $156(47 \%)$ & $<0.001$ \\
\hline \multicolumn{4}{|l|}{ Admission characteristics } \\
\hline ICU admission & $80(46 \%)$ & $160(48 \%)$ & 0.592 \\
\hline ICU needs & $66(38 \%)$ & $142(43 \%)$ & 0.269 \\
\hline Misdiagnosis & $37(7 \%)$ & $2(1 \%)$ & $<0.001$ \\
\hline \multicolumn{4}{|l|}{ Length of stay, days } \\
\hline Mean & 6 & 13 & $<0.001$ \\
\hline Median (range) & $4(1-57)$ & $11(1-86)$ & \\
\hline Mean days to surgery & & 4 & \\
\hline Surgery w/in 24 hrs & & $73(22 \%)$ & \\
\hline \multicolumn{4}{|l|}{ Admitting diagnosis } \\
\hline Brain tumor & $51(29 \%)$ & $91(28 \%)$ & 0.681 \\
\hline Vascular lesion & $53(30 \%)$ & $90(27 \%)$ & 0.450 \\
\hline Spine lesion & $36(21 \%)$ & $90(27 \%)$ & 0.105 \\
\hline Wound complication & $7(4 \%)$ & $22(7 \%)$ & 0.226 \\
\hline Hydrocephalus & $15(9 \%)$ & $30(9 \%)$ & 0.860 \\
\hline Other & $12(7 \%)$ & $7(2 \%)$ & 0.007 \\
\hline \multicolumn{4}{|l|}{ Disposition } \\
\hline Home & $102(59 \%)$ & $133(40 \%)$ & $<0.001$ \\
\hline Hospital & $17(10 \%)$ & $41(12 \%)$ & 0.375 \\
\hline SNF/rehabilitation & $34(19 \%)$ & $140(43 \%)$ & $<0.001$ \\
\hline Hospice & $7(4 \%)$ & $2(1 \%)$ & 0.006 \\
\hline Death & $14(8 \%)$ & $14(4 \%)$ & 0.076 \\
\hline Mean total cost & $\$ 30,251$ & $\$ 94,281$ & $<0.001$ \\
\hline
\end{tabular}

SNF = skilled nursing facility.

Values are presented as the number of patients unless stated otherwise.

$1 \%$ among ED patients and 0\% among inpatient referrals, with an identical mean length of stay (13 days). Although a higher portion of inpatient transfers ultimately underwent surgery ( $75 \%$ vs $57 \%, \mathrm{p}<0.001)$, surgery within 24 hours was more common among ED transfers (20\% vs $8 \%$, p < 0.001 ) and the mean time to surgery was shorter (3 vs 5 days; $p<0.001)$. The rate of surgical treatment of vascular lesions was higher among ED referrals (35\% vs $21 \%$, p = 0.005). Results of these comparisons are summarized in Tables 3 and 4.

\section{Analysis of Nonoperative Transfers}

Among nonoperative transfers stratified by point of origin, there were no significant differences in age $(\mathrm{p}=$ $0.898)$, sex $(p=0.361)$, or urgency $(p=0.526)$ between ED and inpatient referrals. A subset of nonoperative transfer patients $(\mathrm{n}=18,10 \%)$ had a surgical lesion that was managed electively and were discharged home and returned for surgery at a mean of 16 days after discharge (median 12, IQR 6-23 days; range 3-67 days). The percentage of 
TABLE 3. Comparison of all ED versus inpatient transfers

\begin{tabular}{|c|c|c|c|}
\hline Variable & $\begin{array}{c}E D \\
(n=273)\end{array}$ & $\begin{array}{l}\text { Inpatient Unit } \\
\quad(n=231)\end{array}$ & $\begin{array}{c}p \\
\text { Value }\end{array}$ \\
\hline Mean age, yrs (range) & $54(21-92)$ & $56(19-91)$ & 0.110 \\
\hline Female sex & $147(54 \%)$ & $118(51 \%)$ & 0.536 \\
\hline Emergency transfer & $34(12 \%)$ & $21(9 \%)$ & 0.228 \\
\hline \multicolumn{4}{|l|}{ Admission characteristics } \\
\hline ICU admission & $153(56 \%)$ & $87(38 \%)$ & $<0.001$ \\
\hline ICU needs & $138(51 \%)$ & $70(30 \%)$ & $<0.001$ \\
\hline Misdiagnosis & $29(11 \%)$ & $10(4 \%)$ & 0.008 \\
\hline \multicolumn{4}{|l|}{ Length of stay, days } \\
\hline Mean & 10 & 12 & 0.012 \\
\hline Median (range) & $7(1-86)$ & $10(1-58)$ & \\
\hline Surgery & $156(57 \%)$ & $174(75 \%)$ & $<0.001$ \\
\hline w/in 24 hrs & $55(20 \%)$ & $18(8 \%)$ & $<0.001$ \\
\hline Mean days to surgery & 3 & 5 & $<0.001$ \\
\hline \multicolumn{4}{|l|}{ Admitting diagnosis } \\
\hline Brain tumor & $71(26 \%)$ & $71(31 \%)$ & 0.240 \\
\hline Vascular lesion & $95(35 \%)$ & $48(21 \%)$ & 0.001 \\
\hline Spine lesion & $50(18 \%)$ & $76(33 \%)$ & $<0.001$ \\
\hline Wound complication & $17(6 \%)$ & $12(5 \%)$ & 0.620 \\
\hline Hydrocephalus & $28(10 \%)$ & $17(7 \%)$ & 0.256 \\
\hline Other & $12(4 \%)$ & $7(3 \%)$ & 0.423 \\
\hline \multicolumn{4}{|l|}{ Disposition } \\
\hline Home & $147(54 \%)$ & $88(38 \%)$ & $<0.001$ \\
\hline Hospital & $11(4 \%)$ & $47(20 \%)$ & $<0.001$ \\
\hline SNF/rehabilitation & $93(34 \%)$ & $81(35 \%)$ & 0.814 \\
\hline Hospice & $7(3 \%)$ & $2(1 \%)$ & 0.151 \\
\hline Death & $15(5 \%)$ & $13(6 \%)$ & 0.948 \\
\hline Mean total cost & $\$ 67,650$ & $\$ 77,523$ & 0.112 \\
\hline
\end{tabular}

Values are presented as the number of patients unless stated otherwise.

patients in this discharge and return for surgery subset was similar among ED and inpatient transfers (11\% vs 9\%, p $=0.634$ ), as was the mean time to surgery ( 21 vs 8 days, $\mathrm{p}=0.167)$.

Among these nonoperative transfer patients, rates of misdiagnosis were higher among ED referrals (23\% vs $18 \%, \mathrm{p}=0.403$ ), while the mean length of stay was higher among inpatient referrals ( 8 vs 5 days, $p=0.010$ ). ED referral patients had a trend toward higher rates of vascular lesions $(35 \%$ vs $21 \%, \mathrm{p}=0.060)$, significantly lower rates of spine lesions (13\% vs 36\%, p < 0.001), and similar rates of brain tumors $(29 \%$ vs $30 \%, \mathrm{p}=0.917)$. ED patients were more likely to be discharged home $(68 \%$ vs $40 \%$, p $=0.001$ ). Inpatient transfers were associated with a higher total cost than transfers from the ED $(\$ 25,086$ vs $\$ 30,267$, $\mathrm{p}=0.037$ ). These data, summarized in Table 5, identify a cohort of patients in which transfer to our facility may have been avoided and replaced by urgent booking into our clinics followed by elective surgery.

Reasons for nonoperative management varied by diagnosis and are summarized in Fig. 2. Among the 51 patients with nonoperative brain tumors, $16(31 \%)$ received chemotherapy or radiation therapy, $10(20 \%)$ returned for elective
TABLE 4. Comparison of operative cases by referral location

\begin{tabular}{|c|c|c|c|}
\hline Variable & $\begin{array}{c}\text { ED } \\
(n=156)\end{array}$ & $\begin{array}{l}\text { Inpatient Unit } \\
\quad(\mathrm{n}=174)\end{array}$ & $\begin{array}{c}p \\
\text { Value }\end{array}$ \\
\hline Mean age (range), yrs & $53(21-84)$ & $57(19-88)$ & 0.037 \\
\hline Female sex & $85(54 \%)$ & $92(53 \%)$ & 0.769 \\
\hline Emergency transfer & $20(13 \%)$ & $16(9 \%)$ & 0.292 \\
\hline \multicolumn{4}{|l|}{ Admission characteristics } \\
\hline ICU admission & $93(60 \%)$ & $67(39 \%)$ & $<0.001$ \\
\hline ICU needs & $88(56 \%)$ & $54(31 \%)$ & $<0.001$ \\
\hline Misdiagnosis & $2(1 \%)$ & 0 & 0.134 \\
\hline \multicolumn{4}{|l|}{ Length of stay, days } \\
\hline Mean & 13 & 13 & 0.742 \\
\hline Median (range) & $11(1-86)$ & $11(2-58)$ & \\
\hline \multicolumn{4}{|l|}{ Surgery } \\
\hline w/in 24 hrs & $55(35 \%)$ & $18(10 \%)$ & $<0.001$ \\
\hline Mean days to surgery & 3 & 5 & $<0.001$ \\
\hline \multicolumn{4}{|l|}{ Admitting diagnosis } \\
\hline Brain tumor & 37 (24\%) & $54(31 \%)$ & 0.138 \\
\hline Vascular lesion & $54(35 \%)$ & $36(20 \%)$ & 0.005 \\
\hline Spine lesion & $35(22 \%)$ & $55(32 \%)$ & 0.062 \\
\hline Wound complication & $12(8 \%)$ & $10(6 \%)$ & 0.479 \\
\hline Hydrocephalus & $16(10 \%)$ & $14(8 \%)$ & 0.486 \\
\hline Other & $2(1 \%)$ & $5(3 \%)$ & 0.316 \\
\hline \multicolumn{4}{|l|}{ Disposition } \\
\hline Home & $68(44 \%)$ & $65(37 \%)$ & 0.249 \\
\hline Hospital & $9(6 \%)$ & $32(18 \%)$ & 0.001 \\
\hline SNF/rehabilitation & $72(46 \%)$ & $68(39 \%)$ & 0.194 \\
\hline Hospice & $1(0.6 \%)$ & $1(0.6 \%)$ & 0.938 \\
\hline Death & $6(3 \%)$ & $8(5 \%)$ & 0.735 \\
\hline Mean total cost & $\$ 99,574$ & $\$ 89,536$ & 0.205 \\
\hline
\end{tabular}

Values are presented as the number of patients unless stated otherwise.

surgery, $9(18 \%)$ were deemed poor surgical candidates, and $3(6 \%)$ were misdiagnosed. In 13 cases $(25 \%)$ surgery was not indicated; this included 9 admissions for postoperative seizures or altered mental status that were managed medically, 2 cases of radiation necrosis, and 2 tumors managed medically (lymphoma and prolactinoma). All of these patients were evaluated by our neuro-oncology team, which provides an additional layer of expertise and facilitates the appropriate chemotherapy or radiation therapy regimens. Among the 53 patients with vascular lesions or intracranial hemorrhages, 28 (53\%) had negative findings on angiography and $7(13 \%)$ were deemed poor surgical candidates due to their neurological examination results on arrival. In 6 cases (11\%), patients received an external ventricular drain and in 2 cases (4\%), patients underwent endovascular treatment. There were 8 misdiagnoses $(15 \%)$ and 2 patients (4\%) who returned for elective clipping of unruptured aneurysms. Among 36 patients with spine lesions, $11(31 \%)$ were managed nonoperatively with bracing of fractures or epidural steroid injections for pain. There were 8 cases $(22 \%)$ of osteomyelitis/discitis that were treated with antibiotics alone, and 3 tumors (8\%) that underwent biopsies and, based on pathology, were sched- 
TABLE 5. Comparison of nonoperative cases by referral location

\begin{tabular}{|c|c|c|c|}
\hline Variable & $\begin{array}{c}\text { ED } \\
(n=117)\end{array}$ & $\begin{array}{c}\text { Inpatient } \\
\text { Unit }(n=57)\end{array}$ & $\begin{array}{c}p \\
\text { Value }\end{array}$ \\
\hline Mean age (range), yrs & $56(22-92)$ & $56(22-91)$ & 0.898 \\
\hline Female sex & $62(53 \%)$ & $26(46 \%)$ & 0.361 \\
\hline Emergency transfer & $14(12 \%)$ & $5(9 \%)$ & 0.526 \\
\hline \multicolumn{4}{|l|}{ Admission characteristics } \\
\hline ICU admission & $60(51 \%)$ & $20(35 \%)$ & 0.044 \\
\hline ICU needs & $50(43 \%)$ & $16(28 \%)$ & 0.061 \\
\hline Misdiagnosis & $27(23 \%)$ & $10(18 \%)$ & 0.403 \\
\hline \multicolumn{4}{|l|}{ Length of stay, days } \\
\hline Mean & 5 & 8 & 0.010 \\
\hline Median (range) & $4(1-31)$ & $6(1-57)$ & \\
\hline Return for elective surgery & $13(11 \%)$ & $5(9 \%)$ & 0.634 \\
\hline \multicolumn{4}{|c|}{ Days from discharge to surgery } \\
\hline Mean & 21 & 8 & 0.167 \\
\hline Median (range) & $16(4-67)$ & $4(3-26)$ & \\
\hline \multicolumn{4}{|l|}{ Admitting diagnosis } \\
\hline Brain tumor & $34(29 \%)$ & $17(30 \%)$ & 0.917 \\
\hline Vascular lesion & $41(35 \%)$ & $12(21 \%)$ & 0.060 \\
\hline Spine lesion & $15(13 \%)$ & $21(36 \%)$ & $<0.001$ \\
\hline Wound complication & $5(4 \%)$ & $2(4 \%)$ & 1.000 \\
\hline Hydrocephalus & $12(10 \%)$ & $3(5 \%)$ & 0.391 \\
\hline Other & $10(9 \%)$ & $2(4 \%)$ & 0.341 \\
\hline \multicolumn{4}{|l|}{ Disposition } \\
\hline Home & $79(68 \%)$ & $23(40 \%)$ & 0.001 \\
\hline Hospital & $2(2 \%)$ & $15(26 \%)$ & $<0.001$ \\
\hline SNF/rehabilitation & $21(18 \%)$ & $13(23 \%)$ & 0.448 \\
\hline Hospice & $6(5 \%)$ & $1(2 \%)$ & 0.429 \\
\hline Death & $9(8 \%)$ & $5(9 \%)$ & 0.775 \\
\hline Mean total cost & $\$ 25,086$ & $\$ 30,267$ & 0.037 \\
\hline
\end{tabular}

Values are presented as the number of patients unless stated otherwise.

uled for chemotherapy or radiation therapy. Three patients were deemed poor surgical candidates (8\%), 2 returned for elective surgery (6\%), and 2 refused surgical intervention (6\%). There were 7 misdiagnoses (19\%). Among the 7 nonoperative wound complications, 3 were misdiagnoses (37\%), 2 were infections treated with antibiotics (25\%), and 2 were treated with minor procedures (25\%; a blood patch for CSF leak and an aspiration and wrapping of a pseudomeningocele). There were 15 transfers for hydrocephalus or shunt failure, which had been misdiagnosed in 12 cases (80\%). Two patients (13\%) with idiopathic intracranial hypertension were scheduled for outpatient follow-up. One patient $(7 \%)$ underwent external ventricular drainage and was eventually weaned without the need for shunting.

\section{Disposition}

The mean length of stay among all patients was 10 days with a range of 1-86 days (median 9 days, IQR 5-14 days). The service at discharge was neurosurgery in 456 cases $(90.5 \%)$, medicine or neurology in 45 cases $(8.9 \%)$, and other surgical services in 3 cases $(0.6 \%)$. The most com- mon disposition was home in 235 cases (46.6\%), followed by skilled nursing facility or rehabilitation in 174 cases (34.5\%), original referring hospital in 58 cases (11.5\%), and hospice in 9 cases (1.8\%). Twenty-eight patients $(5.6 \%)$ had died. There were significant differences when comparing operative and nonoperative patients, with a higher percentage of nonoperative patients going home $(59 \%$ vs $40 \%$, p < 0.001 ) and a higher percentage of operative patients going to rehabilitation or skilled nursing facility ( $43 \%$ vs $19 \%$; $\mathrm{p}<0.001)$. Among all patients, those from the ED had a higher rate of discharge home than those with inpatient referrals (54\% vs 38\%, p < 0.001), even among those who underwent surgery ( $45 \%$ vs $36 \%$, $\mathrm{p}<0.001)$.

\section{Comparison of Elective and Transfer Admissions}

We examined a separate cohort of patients discharged over the same 12-month period. This consisted of 1986 elective admissions, 248 patients admitted from our own $\mathrm{ED}$, and 504 transfer patients. Rates of surgical intervention were $98 \%$ for elective admissions, $61 \%$ for ED admissions, and $65 \%$ for transfer admissions $(\mathrm{p}<0.001)$. The mean length of stay was shorter among elective and ED patients (4 and 7 days) than among transfer patients (10 days), a difference that was statistically significant $(p<0.001)$. Length of ICU stay was also shorter (1 vs 2 vs 4 days, respectively; $\mathrm{p}<0.001$ ). The proportion of patients with commercial insurance was highest among elective patients (46\%) compared with ED patients (39\%) and transfer patients (28\%), which was significant $(\mathrm{p}<0.001)$. The total cost of admission was higher among transfer patients $(\$ 72,175)$ than among elective $(\$ 44,412)$ and ED $(\$ 46,163)$ admissions (p $<0.001)$. These data are summarized in Table 6.

\section{Discussion}

Interfacility neurosurgical transfers represent an important component of the neurosurgical volume at tertiary care centers and can account for up to one-third of patients admitted to a given neurosurgical ICU., 1,3,6,8 Many transfers are thought to stem from a lack of local neurosurgeons or resources such as 24-hour MRI availability. In a survey of ED directors, $49 \%$ reported a lack of on-call physician specialists as a serious problem. ${ }^{16}$ As the care of acute and complex neurosurgical ailments becomes centralized to tertiary care centers based on evidence supporting improved outcomes, there will be a growing need for neurosurgical transfers, particularly for patients requiring immediate, life-sustaining interventions. ${ }^{47,10,14}$ In our cohort, $15 \%$ of all patients underwent surgery within 24 hours. While an additional $50 \%$ of patients ultimately required surgery during the transfer admission, rates of surgery were significantly higher among inpatient referrals, and rates of misdiagnosis were higher among ED transfers. These findings, combined with the increased cost and decreased profit margin associated with inpatient transfers, underscore the benefit of local medical centers thoroughly evaluating patients by admitting them before committing to transfer whenever possible.

The indications for neurosurgical transfer often vary by the diagnosis. For acute hemorrhages, there is little debate over the necessity of transfer to a facility with neurosurgical and neurocritical care for both diagnostic and thera- 

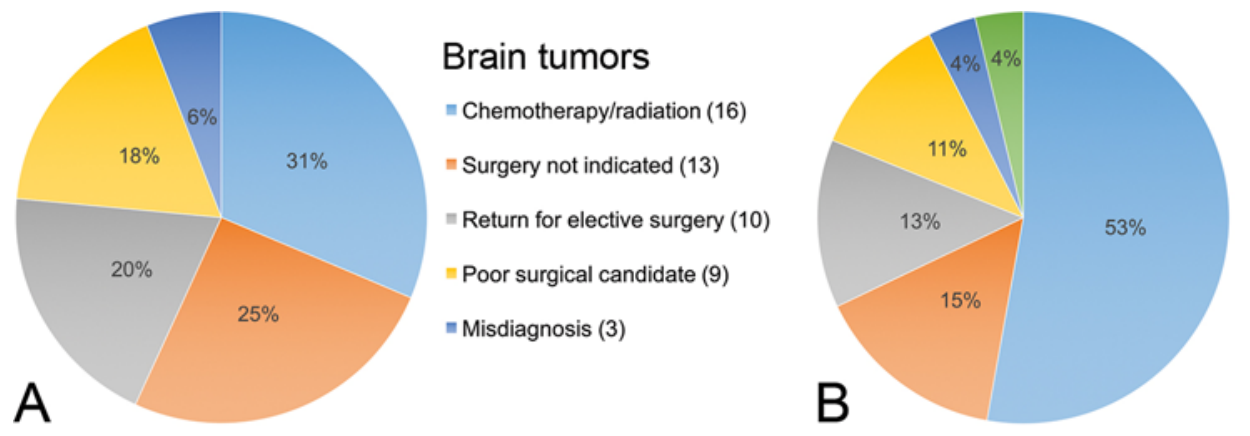

\author{
Vascular \\ " Angiographically negative (28) \\ " Misdiagnosis (8) \\ = Poor surgical candidate (7) \\ = EVD only (6) \\ " Return for elective surgery (2) \\ " Endovascular treatment (2)
}

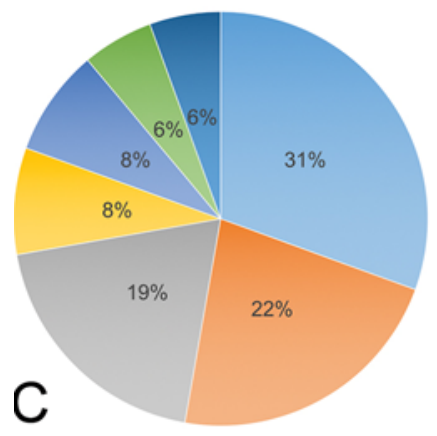

\title{
Spine
}

= Non-operative management (11)

= Treatment with antibiotics (8)

Misdiagnosis (7)

- Chemotherapy/radiation (3)

- Poor surgical candidate (3)

= Return for elective surgery (2)

= Patient refused surgery (2)

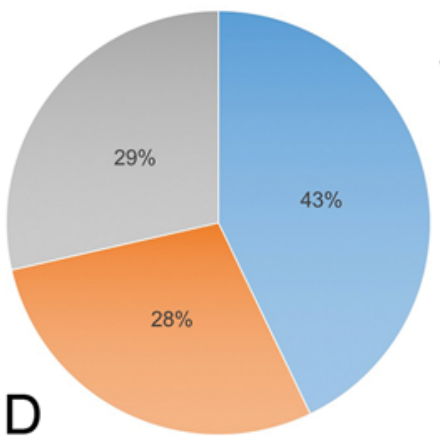

Wound complications

" Misdiagnosis (3)

" Antibiotics (2)

" Bedside procedure (2)
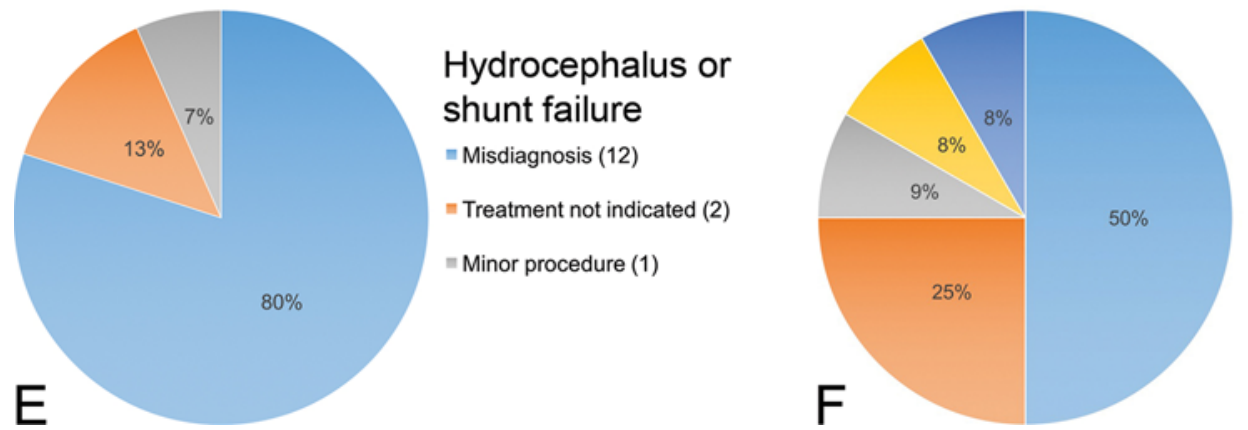

\section{Other diagnoses}

" Surgery not indicated (6)

" Misdiagnosis (3)

= Return for elective

surgery (1)

Antibiotics (1)

= Bedside procedure (1)

FIG. 2. Reasons for nonoperative management of transfer patients. Pie charts represent the reasons for nonoperative management of patients with brain tumors (A), vascular lesions or intracranial hemorrhage (B), spine lesions (C), wound complications (D), hydrocephalus or shunt failure $(\mathbf{E})$, or other diagnoses $(\mathbf{F})$. Figure is available in color online only.

peutic interventions; however, the timing for brain tumors or spinal disorders can be more subjective. New neurological deficit or concern for cauda equina syndrome certainly warrants neurosurgical transfer, particularly in cases in which referring facilities lack MRI. For other cases such as osteomyelitis/discitis, many of which are initially managed nonoperatively, referring facilities often lack interventional radiology to perform a biopsy prior to starting antibiotic therapy. Patients with wound complications are often transferred since this type of complication should be managed by the primary surgeon, even if the management is not operative. For cases of hydrocephalus or possible shunt failure, referring facilities may lack the expertise for evaluating shunts, performing shunt taps, or sophisticated diagnostics such as nuclear medicine shunt studies.

Perhaps the most significant factor related to neurosurgical transfer requests from outside EDs is the Emergency Medical Treatment and Active Labor Act (EMTALA). Under this law, any patient presenting to an ED must be stabilized and treated. This poses unique challenges for neurosurgical patients since smaller community-based
TABLE 6. Comparison of elective and ED admissions at our institution and transfer admissions

\begin{tabular}{lcccc}
\hline \multicolumn{1}{c}{ Variable } & $\begin{array}{c}\text { Elective } \\
(\mathrm{n}=1986)\end{array}$ & $\begin{array}{c}\text { ED } \\
(\mathrm{n}=248)\end{array}$ & $\begin{array}{c}\text { Transfer } \\
(\mathrm{n}=504)\end{array}$ & $\begin{array}{c}\mathrm{p} \\
\text { Value }\end{array}$ \\
\hline Operative case & $1937(98 \%)$ & $152(61 \%)$ & $330(65 \%)$ & $<0.001$ \\
\hline Length of stay, days & & & & \\
\hline Mean & 4 & 7 & 10 & $<0.001$ \\
\hline Median (range) & $3(1-52)$ & $5(1-80)$ & $9(1-86)$ & \\
\hline ICU stay, days & \multicolumn{5}{c}{4} & $<0.001$ \\
\hline Mean & 1 & 2 & 4 & \\
\hline Median (range) & $0(0-26)$ & $0(0-47)$ & $2(0-39)$ & \\
\hline Insurance type & & & & \\
\hline Commercial & $914(46 \%)$ & $98(39 \%)$ & $140(28 \%)$ & $<0.001$ \\
\hline Medicare & $667(34 \%)$ & $94(38 \%)$ & $193(38 \%)$ & 0.080 \\
\hline Medi-Cal & $382(19 \%)$ & $54(22 \%)$ & $164(33 \%)$ & $<0.001$ \\
\hline Other & $23(1 \%)$ & $2(1 \%)$ & $7(1 \%)$ & 0.781 \\
\hline Total cost & $\$ 44,412$ & $\$ 46,163$ & $\$ 72,175$ & $<0.001$ \\
\hline Val & & &
\end{tabular}

Values are presented as the number of patients unless stated otherwise. 
hospitals lack the capacity to stabilize these patients, even when their diseases do not require the expertise of a tertiary care center. In some cases, these hospitals would have the capacity to care for these patients during regular business hours but lack specialty care or full imaging services overnight. More insidious reasons for transfer may exist outside of medical need since there are reports that uninsured patients are more likely to be transferred for neurosurgical issues; however, our data showed no difference among insurance types between ED and inpatient transfers. ${ }^{2,17,18}$

Our cohort provides an example of transfer patient demographics for a major urban academic tertiary center. The most common single diagnosis was primary brain tumor, which differs from previous studies that cited intracranial hemorrhage as the most common transfer diagnosis. ${ }^{6,8}$ Our cohort differs since our main academic hospital is not a trauma center; instead, our institution has a separate Level I trauma center that serves the entire metropolitan area. In our cohort, $64 \%$ of patients underwent surgery, which is higher than the rate in other published studies. ${ }^{6,20}$

Transfer patients accounted for $11 \%$ of the surgical cases requiring inpatient hospitalization during the study period (347 of 2792 cases), and placed a nontrivial burden on the accepting facility, particularly with respect to ICUlevel care that in some cases is not necessary. Holland et al. reported that $7.9 \%$ of patients initially admitted to the ICU were immediately transferred to a lower level of care after arrival and another $16.6 \%$ of patients were transferred out within 24 hours, indicating inappropriate triage. ${ }^{6} \mathrm{Kuhn}$ et al. identified a group of potentially avoidable transfer patients who in retrospect did not require additional workup or neurosurgical intervention and found that $70 \%$ of these patients had been admitted to the ICU. ${ }^{8}$ In our cohort, $12 \%$ of patients admitted to the ICU did not have documented ICU needs and were transferred to a lower level of care within 24 hours. ED transfers had a higher rate of ICU admissions, as our practice is to err toward a higher level of care for patients referred from an ED since they have not been evaluated by a neurosurgeon and may still require additional imaging or medical workup. The ED cohort had a higher percentage of intracranial hemorrhages, and we suspect that ED patients had more severe symptoms or disease processes compared with inpatient referrals; however, this is based on anecdotal experience since the study was not specifically designed to address this issue.

We suspect that the rate of inappropriate ICU triage among the inpatient referrals was due to the higher rate of brain tumors, many of which present with altered mental status or seizures. However, these symptoms can improve over the course of 1-2 days-in some cases, hours-after initiation of high-dose corticosteroids and at the time of arrival to our facility may be completely resolved. Referring facilities, due to their lack of comfort in managing these patients, may also place them in a higher level of care that our team does not deem necessary.

Inappropriate triage can originate from ineffective communication or incomplete workup by the referring facility, with as many as $10 \%$ of patients carrying an incorrect diagnosis. ${ }^{6}$ Our cohort had an overall misdiagnosis rate of $8 \%$, which was higher among ED than inpatient referrals (11\% vs $4 \%$ ). This was driven largely by an incorrect diagnosis of hydrocephalus or shunt failure, brain or spinal tumors, and wound complications. Another burden is the time of day during which these patients arrive to an accepting facility. While most requests for interfacility transfer occur during regular business hours, ${ }^{6}$ patients often do not arrive until the evening or early morning due to bed availability, which places additional stress on the limited staff available to care for these patients. ${ }^{3,6}$ Vedantam et al. found that the majority of transfers occurred outside normal business hours and one-third on weekends. ${ }^{20}$ Emergency cases that require ICU-level care or urgent surgery are an exception, but future studies should address whether there are differences in cost between businesshour and after-hour transfers and whether transfer requests for patients with nonemergency ailments can be safely triaged. In a study of ED-to-ED transfers, over one-third of patients were discharged without admission, observation, or procedures, suggesting a role for telemedicine consults with subspecialists to reduce these transfers. ${ }^{15}$

Although we strive to minimize unnecessary transfers, it is important to note that delays in transfer pose significant risk. Transfer times are cited to range from 4 to 5 hours from the time of initial request or imaging diagnosis to patient arrival. ${ }^{5,6,11,12}$ Byrne et al. found that $15 \%$ of patients had a decline in Glasgow Coma Scale score upon transfer, with a mean time of 5 hours and 3 minutes; 5\% of patients had a Glasgow Coma Scale score decline of 5 points. ${ }^{3}$ For patients requiring emergency intervention, the timing of transfer must be carefully considered prior to acceptance and the referring facility must be counseled on management strategies. There are financial considerations to transferring patients as well. In our comparison of elective patients at our institution and transfer patients admitted over a 12-month period, elective cases were associated with lower total cost compared with transfers over the same period. Part of the increased cost associated with transfer cases versus elective cases is presumably due to the need for more diagnostic studies, medical optimization, and increased length of stay. Since transfer patients cost the receiving hospital significant financial resources, referring facilities must optimize them prior to transfer and bear some of this cost. Another important element of cost not accounted for in our analysis is the cost of transfer, which varies by ambulance company and means of transportation (ambulance, helicopter, or airplane); some estimate that eliminating overtriage of air patients would result in a cost savings of $\$ 1,316,036$ annually. ${ }^{13}$ Kuhn et al. found that the direct transportation costs of avoidable transfers amounted to $\$ 1,460,000$ over 2 years. ${ }^{8}$

Although our study did not address the issue of avoidable transfers in detail, novel approaches and transfer management algorithms are needed to optimize the transfer request system. Kuhn et al. retrospectively identified a subgroup of transfer patients who did not require neurosurgical diagnostic testing, intervention, or intensive monitoring after transfer, which accounted for nearly $20 \%$ of all transferred patients. ${ }^{8}$ These patients either had benign pathology that did not require surgical intervention or had catastrophic injuries for which further ICU management or surgical intervention was futile. Communication is a 
critical issue, and accepting neurosurgeons must be able to rely on a referring facility's neurological examination findings and imaging studies. Integration of electronic medical records may allow for referring facilities to personally review imaging and laboratory studies prior to transfer, thus saving time and minimizing needless repetition of these studies. Telemedicine has also been cited as a potential means to improve communication between providers to ensure that an appropriate level of care is initiated at the accepting facility. ${ }^{6,9,20}$ Such devices would allow direct visualization as an outside provider performs a bedside examination of a patient and review of appropriate imaging. Future studies should aim to develop algorithms that can recognize which patients do not require emergency transfer and determine the utility of telemedicine consults to ease the burden and cost of traditional transfers.

\section{Conclusions}

Data on neurosurgical interfacility transfers are limited. We present a 12-month experience from a single tertiary care academic medical center without a Level I trauma designation. In this cohort, $65 \%$ of patients required surgery; however, rates of surgery were significantly higher among inpatient hospital transfers, and rates of misdiagnosis were significantly higher among ED referrals. Given these findings, admitting nonurgent patients at local hospitals may improve diagnostic accuracy and increase the ability to identify operative cases. However, referring facilities may lack the resources needed for additional workup or may not feel comfortable having these patients admitted while this workup is being pursued; furthermore, EMTALA obligates the tertiary care center to accept patients under these circumstances. Increased use of telemedicine and improved integration of electronic medical records may prevent unnecessary transfers, but future studies are needed to determine the viability and safety of these technologies in the acute care setting.

\section{References}

1. Alaraj A, Esfahani DR, Hussein AE, Darie I, Amin-Hanjani S, Slavin KV, et al: Neurosurgical emergency transfers: an analysis of deterioration and mortality. Neurosurgery 81:240-250, 2017

2. Bekelis K, Missios S, Wong K, MacKenzie TA: The practice of cranial neurosurgery and the malpractice liability environment in the United States. PLoS One 10:e0121191, 2015

3. Byrne RW, Bagan BT, Slavin KV, Curry D, Koski TR, Origitano TC: Neurosurgical emergency transfers to academic centers in Cook County: a prospective multicenter study. Neurosurgery 62:709-716, 2008

4. Cross DT III, Tirschwell DL, Clark MA, Tuden D, Derdeyn $\mathrm{CP}$, Moran CJ, et al: Mortality rates after subarachnoid hemorrhage: variations according to hospital case volume in 18 states. J Neurosurg 99:810-817, 2003

5. Dunn LT: Secondary insults during the interhospital transfer of head-injured patients: an audit of transfers in the Mersey Region. Injury 28:427-431, 1997

6. Holland CM, McClure EW, Howard BM, Samuels OB, Barrow DL: Interhospital transfer of neurosurgical patients to a high-volume tertiary care center: opportunities for improvement. Neurosurgery 77:200-207, 2015

7. Johnston SC: Effect of endovascular services and hospital volume on cerebral aneurysm treatment outcomes. Stroke 31:111-117, 2000

8. Kuhn EN, Warmus BA, Davis MC, Oster RA, Guthrie BL: Identification and cost of potentially avoidable transfers to a tertiary care neurosurgery service: a pilot study. Neurosurgery 79:541-548, 2016

9. Langabeer JR II, Champagne-Langabeer T, Alqusairi D, Kim J, Jackson A, Persse D, et al: Cost-benefit analysis of telehealth in pre-hospital care. J Telemed Telecare 23:747-751, 2017

10. Lawton MT, Du R: Effect of the neurosurgeon's surgical experience on outcomes from intraoperative aneurysmal rupture. Neurosurgery 57:9-15, 2005

11. Leach P, Childs C, Evans J, Johnston N, Protheroe R, King A: Transfer times for patients with extradural and subdural haematomas to neurosurgery in Greater Manchester. Br J Neurosurg 21:11-15, 2007

12. Lind CR, Heppner PA, Robins TM, Mee EW: Transfer of intubated patients with traumatic brain injury to Auckland City Hospital. ANZ J Surg 75:858-862, 2005

13. Madiraju SK, Catino J, Kokaram C, Genuit T, Bukur M: In by helicopter out by cab: the financial cost of aeromedical overtriage of trauma patients. J Surg Res 218:261-270, 2017

14. McLaughlin N, Laws ER, Oyesiku NM, Katznelson L, Kelly DF: Pituitary centers of excellence. Neurosurgery 71:916924, discussion 924-926, 2012

15. Medford-Davis LN, Holena DN, Karp D, Kallan MJ, Delgado MK: Which transfers can we avoid: multi-state analysis of factors associated with discharge home without procedure after ED to ED transfer for traumatic injury. Am J Emerg Med 36:797-803, 2018, 2017

16. Menchine MD, Baraff LJ: On-call specialists and higher level of care transfers in California emergency departments. Acad Emerg Med 15:329-336, 2008

17. Missios S, Bekelis K: The association of unfavorable outcomes with the intensity of neurosurgical care in the United States. PLoS One 9:e92057, 2014

18. Nahed BV, Babu MA, Smith TR, Heary RF: Malpractice liability and defensive medicine: a national survey of neurosurgeons. PLoS One 7:e39237, 2012

19. Nakagawa K, Galati A, Juarez DT: The excess cost of interisland transfer of intracerebral hemorrhage patients. Am J Emerg Med 33:512-515, 2015

20. Vedantam A, Hansen D, Briceño V, Moreno A, Ryan SL, Jea A: Interhospital transfer of pediatric neurosurgical patients. J Neurosurg Pediatr 18:638-643, 2016

\section{Disclosures}

The authors report no conflict of interest concerning the materials or methods used in this study or the findings specified in this paper.

\section{Author Contributions}

Conception and design: Safaee, Berger, Aghi. Acquisition of data: Safaee, Morshed, Spatz. Analysis and interpretation of data: Safaee, Morshed, Spatz, Berger, Aghi. Drafting the article: Safaee, Aghi. Critically revising the article: Safaee, Sankaran, Berger, Aghi. Reviewed submitted version of manuscript: all authors. Approved the final version of the manuscript on behalf of all authors: Safaee. Statistical analysis: Safaee. Administrative/ technical/material support: Berger, Aghi. Study supervision: Aghi.

\section{Correspondence}

Michael Safaee: University of California, San Francisco, CA. michael.safaee@ucsf.edu. 